\title{
Variação da técnica de drenagem do seio maxilar após remoção de corpo estranho pela abordagem descrita por Caldwel-Luc.
}

\author{
Variation for the maxillary antrum drainage after foreign body removal by \\ Caldwell-Luc surgery.
}

\author{
João Carlos B. Wagner * \\ Márcio B. Krüger " \\ Maurício Roth Volkweis *
}

\begin{abstract}
RESUMO
Neste trabalho desenvolve-se uma variaçāo da drenagem do seio maxilar após remoção de corpo estranho pela abordagem de Caldwell-Luc. Três pacientes com dente ou resto radicular introduzidos durante exodontias no seio maxilar foram operados e ao invés de contra-abertura nasal procedeu-se a instalação de sondas para a imigação e aspiração do seio maxilar no período pós-operatório imediato. Conclue-se que: Oemprego de sondas de irrigaçāoe aspiração reflete um avanço na técnica de CaldwellLuc; A lavagem pós-operatória do seio maxilar dispensa a realização de contra-abertura nasal e oferece conforto para o paciente no período pósoperatónio; A cinurgia de Caldwell-Lucé uma técrica segura e de simples execução para a remoção de corpos estranhos do seio maxilar.
\end{abstract}

\section{PALAVRAS-CHAVE}

Seio maxilar, Caldwell-Luc, Corpo estranho.

\section{INTRODUÇÃO}

A técnica cirúrgica de Caldwell-Lucpara acesso ao seio maxilar foi descrita há mais de cem anos e durante este período foi amplamente empregada por cirurgiōes bucomaxilofaciais e otorrinolaringologistas para as mais diferentes finalidades. Todavia, com o advento da videoendoscopia do seio maxilar muitas das suas indicaçōes ficaram superadas (Yanagisawa et al., 1997). Conduto, a remoção de corpos estranhos, em muitas situaçōes, não pode ser procedida por endoscopia. Nestes casos o acesso de Caldwell-Luc permanece como opção de escolha.

Propõe-se apresentar três casos clínicos tratados com uma adaptação da técnica, evitando abertura contra-lateral do seio maxilar e proponcionando extremo conforto para o paciente.

\section{REVISĀO DE LITERATURA}

Rezende e Heitz (1990) afirmam que a remoçāo de corpos estranhos do seio maxilar deve ser feita pelo acesso de Caldwell-Luc, sendo o antro cuidadosamente lavado, através de inrigaçōes e aspiraçōes.

Corpos estranhos podem ser entendidos como dentes ou fragmentos radiculares, material de moldagem como alginato e pasta zinco-enólica, material e instrumentos endodônticos, projéteis de armas de fogo, agulhas de costura, madeira, capim, pedras, vidro e brocas. (Maurel, 1944; Westmark, 1989; Rezende e Heitz, 1990; Abe et al., 1992; Graziani, 1995; Kobayashi, A., 1995; Silveira, 1998)

Os corpos estranhos podem ser classificados em: traumáticos, que seriam projéteis de armas de fogo, vidro, pedras, madeira, capim, etc.; iatrogênicos, representados por dentes e seus fragmentos, pedaços de fóroeps quebrados, material de impressão, gutta-percha, etc. (Abe et al., 1992)

Para Maurel (1944) e Graziani (1995) a remoção do corpo estranho deve ser a mais rápida possível, pois a sua permanência resultaria em sinusite, incurável enquanto durar a presença do material. Todavia, se o material foi introduzido via alvéolo dentário, não deve-se tentar removê-lo por esta via, sob pena de estabelecer ou piorar uma comunicação bucosinusal, além da dificuldade extrema em fazê-lo. (Maurel, 1944; Rezende e Heitz, 1990; Graziani, 1995; Silveira, 1998)

A permanência de material estranho também pode desenvolver aspergilose, que é o crescimento de fungos associado ao corpo estranho. Pode, inclusive, permanecer assintomático. Para a remoção do material e dos fungos está indicado o acesso de Caldwell-Luc. (Kobayashi, A., 1995)

Wooley et al. (1997) relatam um caso onde uma raiz de um pré-molar deslocada para dentro do seio maxilar provocou sinusite paranasal, evoluindo para empiema subdural, que é uma complicação rara das sinusites paranasais. $\mathrm{O}$ paciente permaneceu com hemiplegia facial do lado esquerdo como seqüela da infecção. Este caso, segundo os autores, reforça a necessidade de remoção rápida de raízes do interior do seio maxilar para evitar complicações mais graves.

Segundo Westmark (1989), muitos artigos apresentam indicaçāo de remoção de corpos estranhos pela abordagem de Caldwell-Luc. Todavia, relata um caso onde múltiplos pequenos fragmentos de material de obturação de canal foram espontaneamente eliminados pelo óstium, demonstrando a capacidade da mucosa pseudoestratificada ciliada de transportar pequenos fragmentos do seio maxilar para a fossa nasal.

O êxito da intervenção depende de uma perfeita localização radiográfica, em diferentes planos, podendo o corpo estranho estar solto no seio maxilar, aderido ou insinuado na mucosa. (Maurel, 1944; Graziani, 1995)

Graziani (1995) afirma que somente uma via de acesso permite realizar satisfatoriamente a remoção do corpo estranho, que é a cirurgia de Caldwell-Luc. Silveira (1998) indica que o acesso de Caldwell-Luc deve ser empregado para a remoção de dentes ou raízes do interior do seio maxilar. Abe et al. (1992) relatando a introdução de brocas no seio maxilar também empregou acesso de CaldwellLuc para tratamento do paciente.

Faz-se uma incisão intra-bucal, horizontal, linear no fundo de sulco, estendendo-se de caninoa segundo molar. Após, descola-se mucosa e periósteo, tendo atenção de não lesar o feixe infra-orbitário. Exposto o osso, realiza-se a trepanação do seio pela fossa canina com goiva e martelo realizando um orificio e alargando-o com pinça de Citelli. (Maurel, 1944; Graziani, 1995)

Remove-se o corpo estranho, procede-se a contra-abertura nasal, para que as secreçōes pósoperatórias da cavidade sinusal drenem para a fossa nasal. Esta abertura é realizada na porção mais anterior e inferior da cavidade sinusal, idealmente em seu assoalho, continuando-se com o assoalho da fossa nasal, abaixo do corneto inferior. Deve ter aproximadamente $1 \mathrm{~cm}$ de diâmetro. Sutura-se a mucosa bucal aproximando-se bem as bordas da

\footnotetext{
- Professor Titular de Cirurgia da Universidade Luterana do Brasil, Chefe do Serviço de Cirurgia Bucomaxilofacial do Complexo Hospitalar da Santa Casa de Porto-Alegre.

- Professor Adjunto de Cirurgia da Universidade Luterana do Brasil.

- Professor Adjunto de Cirurgia e Patologia Bucal da Universidade Luterana do Brasil, cirurgiāo do Serviço de Cirurgia Bucomaxilofacial do Complexo Hospitalar da Santa Casa de Porto-Alegre.
}

R. Fac. Odontol., Porto Alcgre, v. 40, n. 1, p. 50-52, set. 1999 
incisão. (Graziani, 1995)

Já em 1944, Maurel descreve que a drenagem por via nasal é uma particularidade da técnica de Caldwell-Luc, ressaltando que procede-se a sutura bucal e drenagem nasal. Como opção haveria a técnica de Lemorier-Desault com drenagem bucal sem sutura e também sem a contra-abertura nasal.

Se houver risco de infecção do seio, Graziani (1995) destaca que pode-se fazer uma lavagem antisséptica não irritante, e nos casos indicados, curetar a mucosa do seio.

Para Rezende e Heitz (1990) e Graziani (1995) deve-se empregar antibioticoterapia no pósoperatório.

\section{MATERIAL EMÉTODOS}

Selecionou-se três pacientes com presença de dentes ou restos radiculares que foram deslocados acidentalmente para o interior do seio maxilar durante procedimentos exodônticos em outros serviços.

O caso l corresponde a uma paciente do sexo feminino de 19 anos de idade que há dois meses sofreu a introdução do 18 para o interior do seio maxilardurante exodontia. (figuras l e 2).

O paciente do caso 2 era do sexo masculino, 40 anos de idade. Apresentava a raiz do 26 introduzida durante exodontia para o interior do seio maxilar há vinte meses. As ilustrações cirúrgicas correspondem a este paciente.

O caso 3 tratava-se de uma paciente do sexo feminino, 53 anos de idade, que apresentava resto radicular do 14 introduzido no interior do seio maxilar durante exodontia há três meses.

Para todos os casos procedeu-se exames por imagem com radiográfia periapical, panorâmica e tele-perfil.

Foi indicado remoção cirúrgica pelo acesso de Caldwell-Luc, sob anestesia geral. Como medicação pré-operatória, prescreveu-se cefalotina, $1 \mathrm{~g} ., \mathrm{EV}, \mathrm{l}$ hora antes do procedimento cirúrgico.

Realizou-se incisão intra-bucal, no fundo de sulco, estendendo-se do canino a mesial do primeiro molar.Após descolamento muco-periósteo, realizouse a osteotomia da parede anterior do seio maxilar com brocas esféricas de haste longa $n^{\circ} .6$, montadas em motor de suspensão. (figura 3 )

Em cada caso, o corpo estranho foi localizado com visão direta, e recolhido com o auxilio de uma pinça de Halsted.

Realizava-se, então, uma tuneilização sob a mucosa vestibular da borda alveolar, indo do local da incisão até o canino contra-lateral, onde uma pequena incisão linear era realizada. Por este túnel, passavam-se duas sondas de aspiração, uma $\mathrm{n}^{\circ} .6 \mathrm{e}$ outra $n^{\circ} .8$ (figura 4 ), ficando uma extremidade localizada na boca, junto a incisão do canino contra-lateral, suturadas na mucosa e a outra extremidade e seu maior comprimento no interior do seio maxilar, após percorrer a extensão do túnel submucoso. (figura 5)

O retalho era reposicionado e suturado com vicryl 4-0. Como prescrição pós-operatória os pacientes receberam cefalotina, $1 . g, E V$, de seis em seis horas e paracetamol associado a $30 \mathrm{mg}$ de codeína, por via oral, de seis em seis horas.
No período pós-operatório, as sondas eram empregadas para irrigação e aspiração do seio maxilar. Pela sonda de menor calibre eram introduzidos $10 \mathrm{ml}$ de soro fisiológico e pela de maior calibre, este conteúdo era aspirado (figura 6). Este procedimento era realizado 3 vezes ao dia. Cada um dos pacientes permaneceu internado por 24 horas pós-operatórias.

No momento da alta hospitalar, ambas as sondas eram removidas. A sutura no local do acesso de Caldwell-Luc era mantida por sete dias. Prescreveu-se cefalexina, $500 \mathrm{mg}$, por via oral, de seis em seis horas, por sete dias e paracetamol, 750 $\mathrm{mg}$, por via oral, de quatro em quatro horas. Fornecia-se ao paciente recomendações pósoperatórias específicas.

\section{RESULTADOS}

Nos três casos relatados neste trabalho obteve-se resultado satisfatório, o que significa a remoção do corpo estranho, conforto e ausência de patologia pós-operatória. O tempo de proservação variou de dois até seis meses, quando os pacientes abandonaram as consultas de controle. Nenhum dos pacientes desenvolveu qualquer intercorrência ou sintomatologia.

O emprego das sondas no periodo pósoperatório permitiu adequada irrigação e aspiração do seio maxilar, resultando na remoção mecânica de sangue, coágulos, secreções e, por conseqüência, mediadores químicos do processo inflamatório. Com o emprego desta variante, não observou-se necessidade de abertura contra-lateral do seio maxilar.

\section{DISCUSSÃO}

A técnica cirúrgica de Caldwell-Luc foi descrita há mais de cem anos, primeiramente para tratamento da sinusite crônica e, com o passar do tempo, novas indicações foram associadas. Todavia, textos clássicos (Maurel, 1944; Rezende e Heitz, 1990; Graziani, 1995) que descrevem a técnica apresentam-a sem variaçōes ou aperfeiçoamentos. Em 1944 (Maurel, 1944), os tempos cirúrgicos descritos são os mesmos observados nos dias atuais.

Entende-se que a utilização de sondas para irrigação e aspiração pós-operatória representam um importante benefício para o paciente porque removem produtos resultantes do ato cirúrgico que gerariam mediadores químicose, por conseqüência, inflamação.

O resultado disto é maior conforto, com menos dor, possibilitando reduzir a analgesia pósoperatória. $\mathrm{O}$ ato de irrigar e aspirar, bem como a remoção das sondas é indolor. Ainda, os produtos que se acumulariam no interior do seio maxilar teriam que ser espontaneamente eliminados ou via óstium, ou via abertura contra-lateral para a fossa nasal, através da movimentação ciliar do epitélio do seio. Sem dúvidas, isto demanda tempo, como demonstrado por Westmark (1989).

A necessidade de uma perfeita localização radiográfica, em diferentes planos, é absolutamente verdadeira e já descrita há mais de cinqüenta anos (Maurel, 1944; Graziani, 1995), logo, tentar remover dentes ou restos radiculares sem estudo por imagens minucioso é aventurar-se.
Acredita-se que a remoção deva ser procedida rapidamente, concordando com o exposto por Maurel (1944), Graziani (1995), Kobayashi (1995) e Wooley et al. (1997).

Com base no exposto por Graziani (1995) e Yanagisawa et al. (1997), define-se que para a remoção de corpos estranhos com volume de dentes ou partes destes, é impraticável sua retirada pelo óstium, por videoendoscopia. Nestas situações, o acesso de Caldwell-Luc é a opção de escolha. O emprego concomitante da videocirurgia com o acesso de Caldwell-Luc facilita a localização do corpo estranho e pode permitir uma menor abertura na parede anterior do seio maxilar.

Pelo sucesso obtido nestes casos, pode-se indicar a técnica de Caldwell-Luc com o emprego de sondas, sem contra-abertura nasal como segura e vantajosa para a remoção de corpos estranhos do seio maxilar, independente de sua natureza.

\section{CONCLUSÕES}

Com base no observado durante a realização deste estudo, pode-se concluir que:

l - O emprego de sondas de irrigação e aspiração reflete um avanço na técnica de CaldwellLuc.

2 - A lavagem pós-operatória do seio maxilar dispensa a realização de contra-abertura nasal e oferece conforto para o paciente no período pósoperatório.

3 - A cirurgia de Caldwell-Lucé uma técnica segura e de simples execução para a remoção de corpos estranhos do seio maxilar.

\section{ABSTRACT}

In this paper, an improvement of the maxillary sinus drainage after the remotion of foreign bodies by Caldwell-Luc surgery is developed. Three patients with tooth or radicular apex introduced into the maxillary antrum during dental extraction were submitted to the surgery. In contrast to the opening to the nasal cavity, two probes were installed to perform the irrigation and aspiration of the antrum after the surgery. The conclusions are that the use of the probes is an advance in the Caldwell-Luc surgery. With the irrigation and aspiration, the opening to the nasal cavity is not necessary and the result is a comfortable recovery to the patient. The Caldwell-Luc surgery is a safe and simple procedure to remove foreign bodies from the maxillary sinus.

\section{KEYWORDS} Body

Maxillary sinus, Caldwell-Luc, Foreing 


\section{REFERÊNCIAS BIBLIOGRÁFICAS}

I. ABE, K., BEEPU, K, SHINOHARA, M., et al. An latrogenic Foreign Body (dental bur) in the Maxillary Antrum: a report of two cases, Brit. Dent. I. London, v. 173 , p. $63-64$, july, 1992

2. GRAZIANI, M., Cirurgia Bucomaxilofacial, Rio de Janeiro: Guanabara Koogan, 8.ed, 1995, 618 p. Cap. 24, Cirurgia do Seio Maxilar, p. 397-418.

3. KOBAYASHI, A., Asymptomatic aspergillosis of the maxillary sinus associated with foreign body of Endodontic Origin, Report of a Case, Int. J. Oral Maxillofac. Surg., Copenhegen, v. 24, n. 3, p. 243244, junho, 1995.

4. MAUREL, G., Cirurgia Maxilo-Facial, Buenos Aires Alfa, 1944, 1163 p., Cap. 12, Tratamiento Quirurgico de las sinusites maxilares, p. 350-385.

5. REZENDE, R.A., HEITZ, C., Comunicações Bucossinusal e Buconasal, In: ZANINI, S. A.,

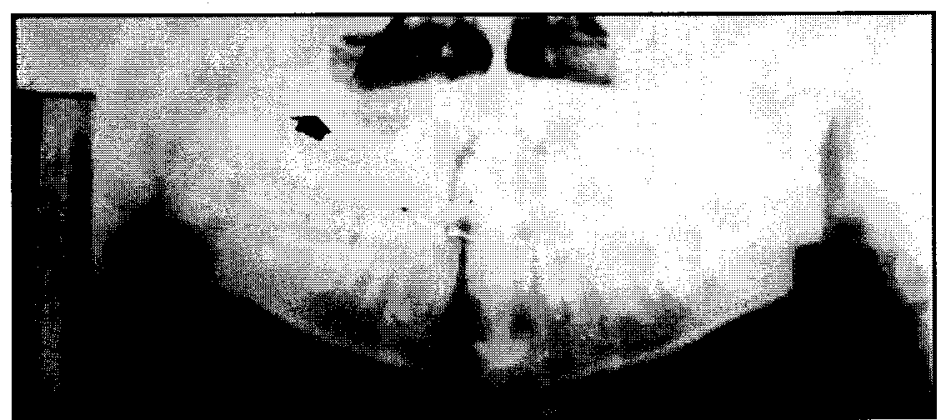

Figura l - Radiografia panorâmica da paciente do caso 1 , onde observa-se o 18 no interior do seio maxilar direito.
Cirurgia e traumatologia bucomaxilofacial, Rio de Janeiro: Revinter, 1990, 464p.,Cap. 25, p. 431448

6. SILVEIRA, J.O.; BELTRĀO, G.C., Exodontia, PortoAlegre: Médica Missau, 1998,430 p., Cap. 23 Acidentes e complicações em exodontias, p. 287-314.

7. WESTMARK, A.H., Spontaneous Removal of Foreign J. Oral Max. Surg., Copenhagen, v. 47, p. 75-77, 1989

WOOLEY, E.J., PATEL, M., Subdural Empyema Resulting from Displacement of a Root into the Maxillary Antrum, Br. Dent. J., London, v. 182, n 11,p. 430-432, june, 1997.

9. YANAGISAWA, E., YANAGISAWA, K, The CaldwellLuc procedure, is it still indicated in this endoscopic surgery era? Ear Nose Throat Journal, v. 76, n. 5, p. 294-296, maio, 1997. Bodies from the Maxillary Sinus: report of a case,

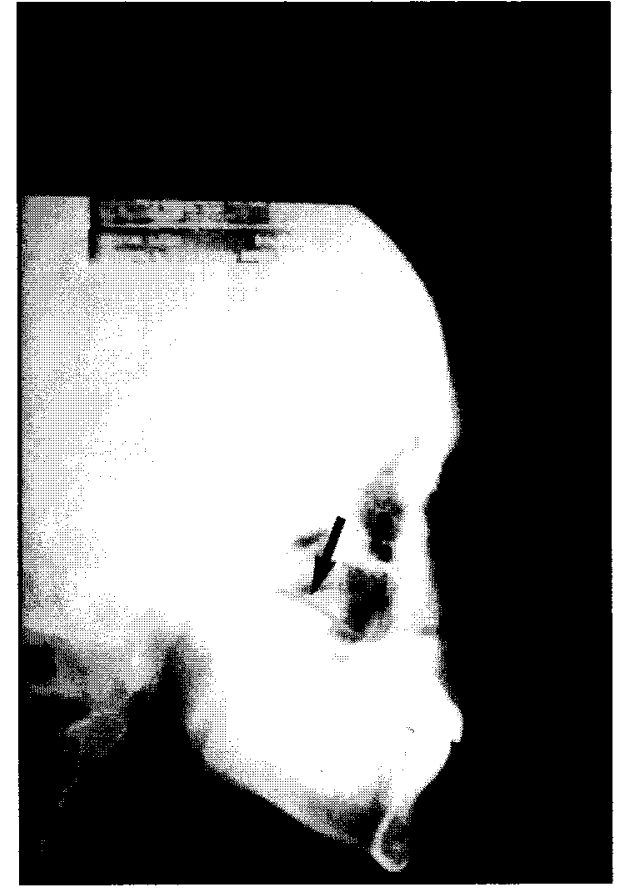

Figura 2 - Perfil radiográfico da paciente do caso 1 , com o 18 no interior do seio maxilar.
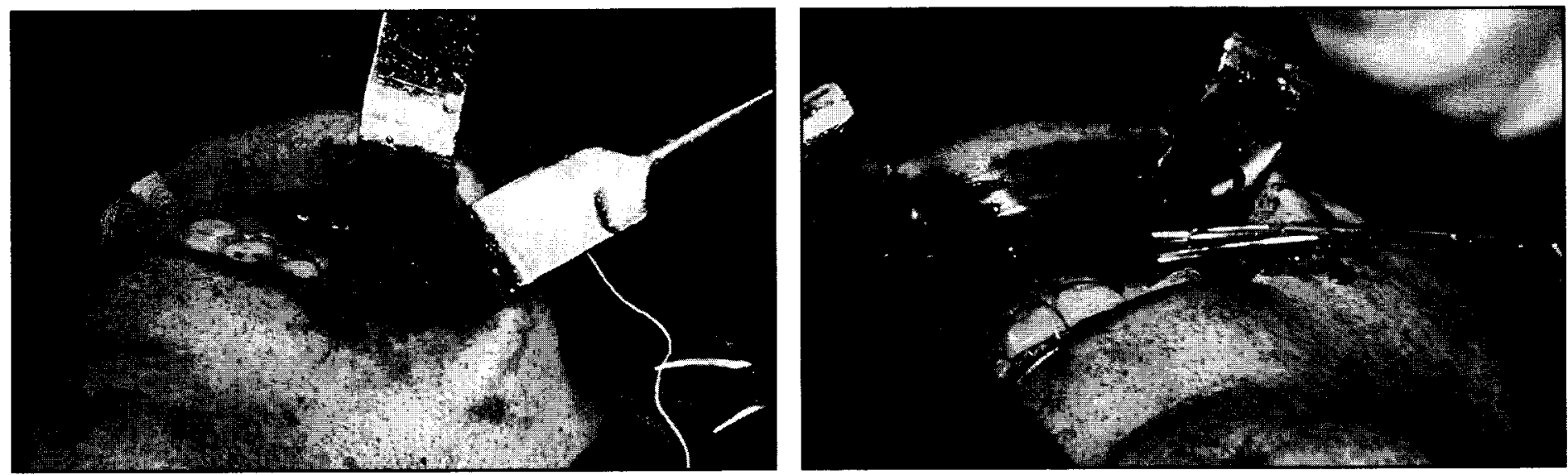

Figura 3 - Osteotomia na parede anterior do seio maxilar.

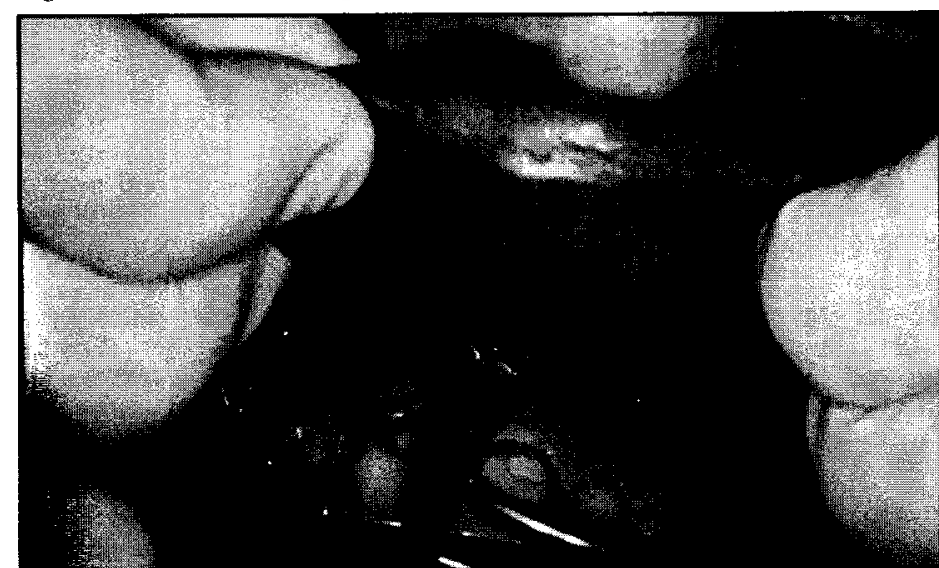

Figura 4 - Tuneilização da mucosa e introdução das sondas aspiradoras.

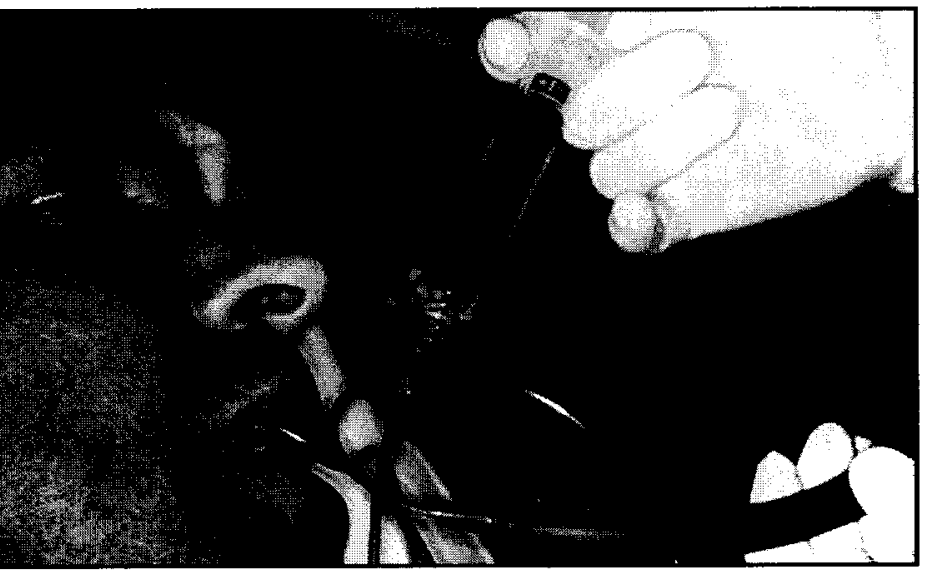

Figura 5 - Sutura do retalho e fixação das sondas por pontos junto a mucosa.

Figura 6 - Procedimento de irrigação e aspiração no pós-operatório, junto ao leito do paciente.

R. Fac. Odontol., Porto Alegre, v. 40, n. 1, p. 50-52, set. 1999 